\title{
Current Status of Quantitative X-ray Microanalysis in VP-ESEM
}

\author{
R. A. Carlton \\ GlaxoSmithKline, King of Prussia, PA 19406
}

Primary electron beam scatter in the VP-ESEM degrades the spatial resolution of qualitative and quantitative chemical analysis using energy dispersive $\mathrm{x}$-ray spectrometry. The resulting $\mathrm{x}$-ray spectrum can include $x$-rays from regions outside the one of interest. Correction procedures have been proposed by Doehne [1], by Bilde-Sorenson and Appel [2], and by Gauvin [3]. Most are dependent upon the observation that $\mathrm{x}$-ray peaks due to scattered electrons increase with increasing chamber pressure whereas $\mathrm{x}$-ray peaks due to the primary electron beam will decrease with increasing chamber pressure. These procedures require collecting spectra at a number of different chamber pressures and correcting to zero pressure. The first two correct the chamber pressure to zero directly whereas the last corrects to zero beam scatter. Doehne has also recently proposed a variant of his previous correction procedure. A summary of the results from the few tests of the correction techniques will be presented here along with some new work with Doehne's correction scheme.

The correction techniques are all capable of producing results in line with expectations for large sized samples. Using $\mathrm{Au} / \mathrm{Cu}$ standards (SRM 482), it was possible to consistently achieve $\pm 3 \%$ relative error for major elements providing the surface charge was monitored and adjusted using a ground path device near the specimen surface [4]. The purpose of this procedure was to achieve a near neutral charge state on the specimen surface. The lower size limit for accurate x-ray analysis has been estimated using SRM 2066 which is composed of glass beads in a range of diameters (4 to $100 \mu \mathrm{m})$. The smallest sized glass bead tested was $7 \mu \mathrm{m}$ which yielded results in line with expectations. The above set of tests comprised a feasibility study and much more study is required in order to fully determine the limits of quantitative analysis using EDS in the VP-ESEM. There are two significant disadvantages to the use of these methods. The first is the necessity of taking measurements at multiple pressures for each sample and standard. It can require as much as 1 hour measurement time for one specimen / standard combination. The second disadvantage is the necessity to extrapolate beyond the measured points.

In Doehne's correction technique, a known element outside the area of interest is used to adjust the spectrum by subtracting spectra at two different pressures. SRM beads pressed into a lead substrate provide a good test of this technique. A $20 \mu \mathrm{m}$ bead was tested a multiple chamber vapor pressures on a Hitachi 3500 VP SEM (see Fig 1). The results are encouraging (see Table 1). Only the oxygen composition was outside the $95 \%$ confidence limits. These results comprise an initial feasibility study. The technique is quite fast and a good strategy may involve testing multiple pressures and doing multiple pressure correction comparisons. The average of such tests may provide a good estimate for elemental compositions for very small particles in the VP-ESEM. 


\section{REFERENCES}

[1] E. Doehne Scanning (1997) 19:75-78.

[2] J.B. Bilde-Soerenson and C.C. Appel 49th Annual Meeting of the Scandinavian Society for Electron Microscopy, Tholen AR (ed.) Svenski i Goteburg AB, Sweden, (1997) 12-15.

[3] R. Gauvin Scanning (1999) 21:388-393.

[4] R.A. Carlton, C.E. Lyman, J.E. Roberts Micros. Microanal. (2004) 10, 753-763.

SRM2066 20 um Sphere in Lead Substrate

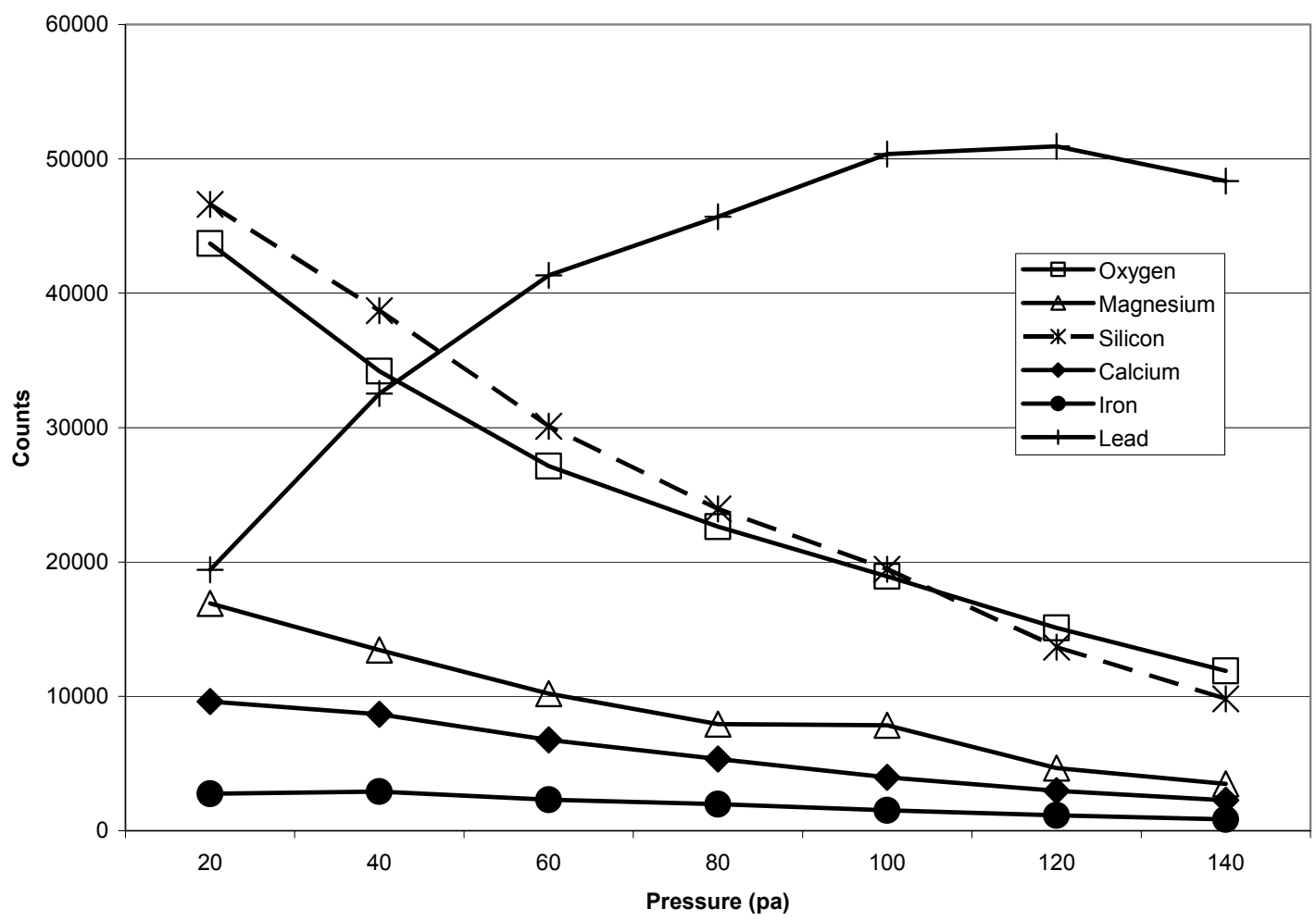

FIG. 1. X-ray count versus chamber pressure relationship for $20 \mu \mathrm{m}$ SRM 2066 bead mounted in a lead substrate.

TABLE 1 Quantitative analysis SRM2066 beads pressed in lead. Pressure - 50 and 130 pa.

\begin{tabular}{|c|c|c|c|c|c|c|}
\hline Results & Oxygen & Magnesium & Silicon & Calcium & Iron & Total \\
\hline k-ratio & 1.036 & 0.991 & 0.963 & 1.014 & 0.855 & \\
\hline Composition (\%) & 44.4 & 9.1 & 24.7 & 11.3 & 9.6 & 99.1 \\
\hline Nominal (\%) & $\begin{array}{c}42.9 \pm \\
1.2\end{array}$ & $\begin{array}{c}9.15 \\
\pm 1.4\end{array}$ & $\begin{array}{c}25.65 \pm \\
1.7\end{array}$ & $\begin{array}{c}11.15 \pm \\
2.4\end{array}$ & $\begin{array}{c}11.2 \pm \\
2.2\end{array}$ & 100 \\
\hline
\end{tabular}

